\title{
Original
}

\section{Distribution of Lidocaine in Alveolar Tissues in Rabbits}

\author{
Takaki Yamazaki, Hideki Mamiya, Tatsuya Ichinohe and Yuzuru Kaneko
}

\begin{abstract}
Department of Dental Anesthesiology, Tokyo Dental College,1-2-2 Masago, Mihama-Ku, Chiba 261-8502 Japan
(Accepted for publication, July 28, 2009)

Abstract: This study was intended to determine the tissue distribution of lidocaine in mandibular mucosa and alveolar bone marrow after local infiltration. Tissue distribution of local anesthetics shortly after regional injection has been unclear. We used macro autoradiography to visually examine the tissue distribution of lidocaine shortly after local anesthetic infiltration. Male Japan White rabbits received an injection of ${ }^{14} \mathrm{C}$-labeled $2 \%$ lidocaine with or without 1:80,000 epinephrine. The areas of infiltration and proportion of distribution 1, 5 and 10 minutes after administration were measured. After the administration of $2 \%$ lidocaine with 1:80,000 epinephrine, infiltration area increased over time. Ratios of distribution in alveolar bone marrow at the level equivalent to the root apex increased in 1 to 5 minutes after administration, and then decreased. In contrast, after the administration of plain lidocaine, infiltration was hardly detected. These results suggest that infiltration of lidocaine with epinephrine diffused to a wider area over time after administration and then gradually absorbed into the capillaries.
\end{abstract}

Key words: Lidocaine, Infiltration, Alveolar bone, Radioisotope

\section{Introduction}

Infiltration anesthesia is widely used for dental treatment. It has been reported that the onset time of local anesthetic action is about 1 - 5 minutes, which is affected by the types and concentration of local anesthetics or vasoconstrictors and the histological structure of the site of administration ${ }^{1-13}$. There were few studies that reported the tissue distribution of local anesthetic after regional injection into oral tissue. Tissue specimens of dogs were observed 15 minutes, 12 hours, and 5 days after administration of a mixture of $2 \%$ lidocaine containing 1:100,000 epinephrine and India ink, injected into the periodontal ligament space ${ }^{14,15)}$. However, these studies did not investigate the tissue distribution of local anesthetics shortly after regional injection.

On the other hand, some studies reported a distribution of local anesthetics in various tissues other than oral tissues ${ }^{16-18)}$. An investigation on the relationship between injected dose and infiltration area 30 minutes after administration of $0.5 \%$ bupivacaine in combination with methylene blue as an intercostal nerve block reported that the distribution of bupivacaine was volume-dependent ${ }^{18}$ ). However, it is difficult to compare the distribution of local anesthetics in the oral region to other tissues because oral tissues include both soft and hard tissues, such as mucosa and alveolar bone, and the specific nerve for dental pulpal

Coresspondence to: Dr. Takaki Yamazaki, Department of Dental Anesthesiology, Tokyo Dental College, 1-2-2 Masago, Mihama-Ku,Chiba 261-8502 Japan. Phone: 81-43-270-3755, Fax: 81-43-270-3756, E-mail: yamazakitakaki@tdc.ac.jp anesthesia runs in the bone marrow.

In the present study, we visually investigated the tissue distribution of lidocaine in mandibular mucosa and alveolar bone marrow shortly after alveolar infiltration by macroautoradiography (macroARG) ${ }^{19-21)}$ using radioisotope (RI) and an imaging-plate. Tissue distribution of lidocaine was compared based on infiltration area and proportion of distribution in selected areas.

\section{Materials and Methods \\ Laboratory animals and preparations}

This study was conducted in compliance with the Guidelines for the Treatment of Experimental Animals at Tokyo Dental College (No. A04-0500-2). Twenty-four 8-10 week-old male Japan White rabbits, weighing between 1.7 and $2.1 \mathrm{~kg}$, were used in this study.

The rabbits were anesthetized with $3.0 \%$ isoflurane (Forane ${ }^{\circledR}$, Abbott Japan, Japan). Tracheostomy was performed using infiltration anesthesia with $0.5 \mathrm{ml}$ of $1 \%$ lidocaine hydrochloride solution (Xylocaine ${ }^{\circledR}$, Astra Zeneca, Japan), and then a $20 \mathrm{Fr}$ pediatric tracheal tube was inserted into the trachea and fixed. A venous indwelling catheter was inserted into the left auricular marginal vein as a route for fluid infusion and drug administration. Acetated Ringer's solution was infused at $10 \mathrm{ml} / \mathrm{kg} / \mathrm{h}$. Anesthesia was maintained by an intermittent intravenous administration of sodium thiopental (Ravonal ${ }^{\circledR}$, Tanabe Pharma, Japan).

Experimented protocol 


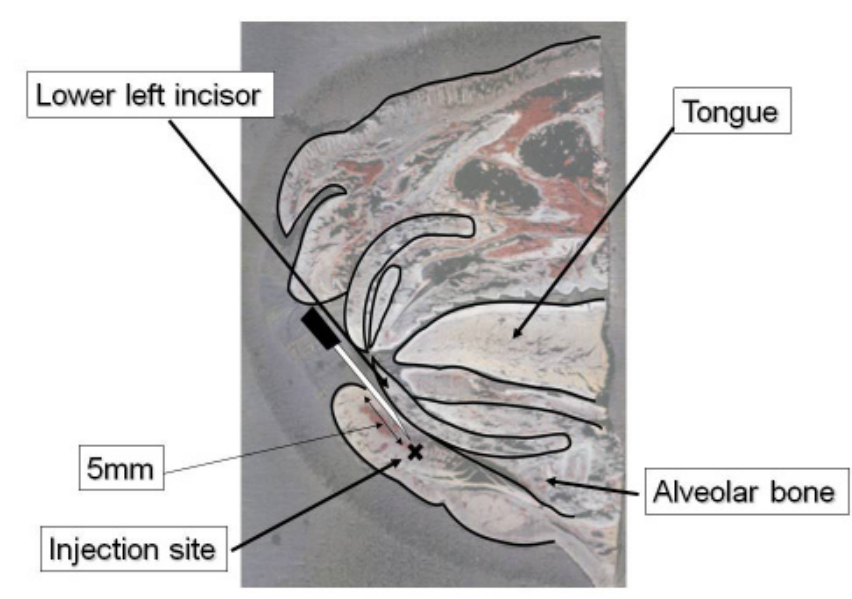

Figure 1. Schema of the injection site. ${ }^{14} \mathrm{C}$-labeled $2 \%$ lidocaine with $1 / 80,000$ epinephrine or without epinephrine $(0.06 \mathrm{ml})$ was injected into the region of vestibular fornix corresponding to the lower left incisor. The injection needle was inserted paraperiosteally to a depth of $5 \mathrm{~mm}$ toward the root apex.

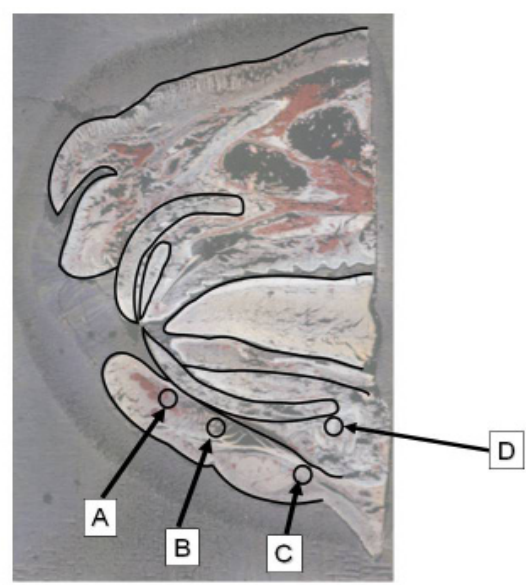

Figure 2. Selected 4 sites to determine the proportion of distribution. A: submucosal tissue of the injection site; B: tissue next to periosteal membrane surrounding alveolar bone (approximately $1 / 2$ of tooth length); C: tissue next to periosteal membrane at a level equivalent to the root apex; D: alveolar bone marrow at a level equivalent to the root apex.
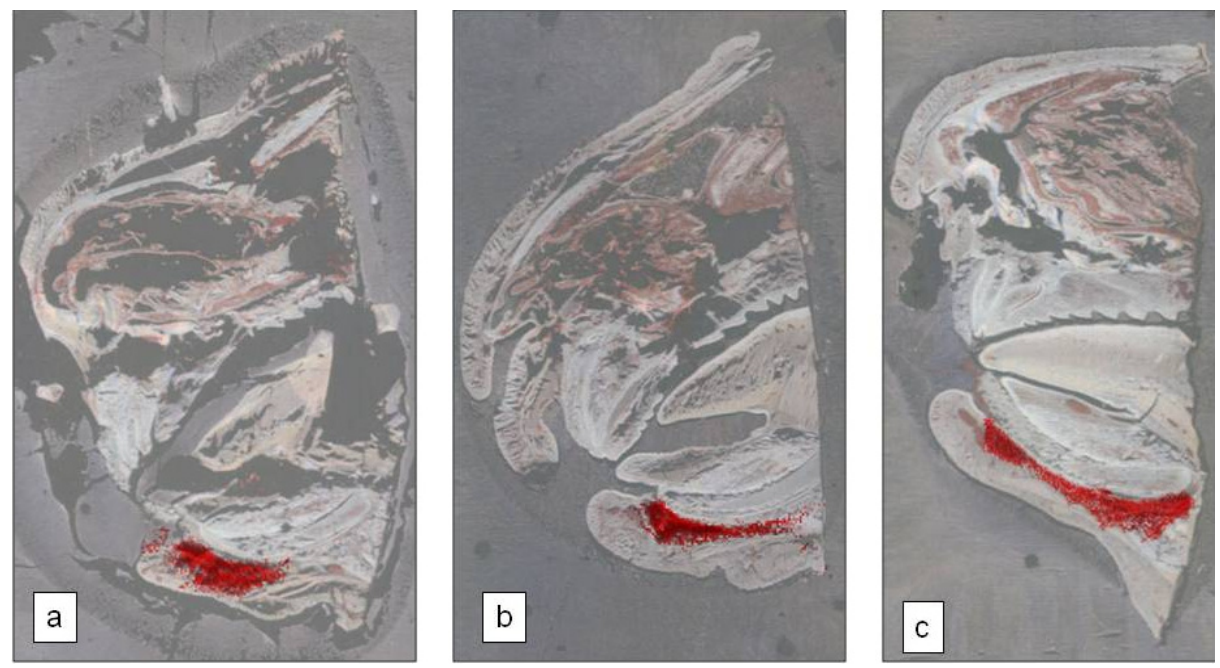

Figure 3. The infiltration area of lidocaine increased over time after administration. a: 1 min after injection; b: 5 min after injection; c: 10 min after injection.

${ }^{14} \mathrm{C}$ was used as a labeled RI because it was commercially available for labeled lidocaine and had an appropriate half-life. Experimental local anesthetic solution consisted of ${ }^{14} \mathrm{C}$-labeled $2 \%$ lidocaine hydrochloride (Bowling Green Drive, U.S.A) with 1:80,000 epinephrine (LE group) or without epinephrine (L group). The concentration of radioactivity was $37 \mathrm{kBq} / \mathrm{ml}$. Local anesthetic solution was injected into vestibular fornix corresponding to the lower left incisor (Fig. 1). The injection needle was inserted paraperiosteally to a depth of $5 \mathrm{~mm}$ toward the root apex. A volume of $0.06 \mathrm{ml}$ was injected using a microsyringe (PB600-1 Repeating Dispenser®, HAMILTON, USA) with a $30 \mathrm{G}$ needle. In the LE group, animals were further divided into 3 groups: 1 minute after administration (LE-1) $(n=6), 5$ minutes after administration (LE-
5) $(n=6)$, and 10 minutes after administration (LE-10) $(n=6)$. Animals in the $\mathrm{L}$ group were also divided corresponding to the above-mentioned three groups (L-1, L-5, L-10) ( $\mathrm{n}=2$, each).

After local anesthetic administration, animals were sacrificed by a fatal dose of sodium thiopental. They were rapidly frozen with liquid nitrogen and the maxilla and the mandible were excised in one peace. These samples were embedded in $8 \%$ carboxymethylcellulose paste, frozen with acetone, cooled in dry ice, and specimen blocks were prepared. Sections of $50 \mu \mathrm{m}$ thickness were prepared using an autocryotome. Sections were set to a graph paper with RI indicator $\left({ }^{241} \mathrm{Am}\right)$ after drying at $20^{\circ} \mathrm{C}$ freezer for $4-5$ days and contacted to an imaging plate for 90 minutes in the imaging cassette. Accumulated images were 


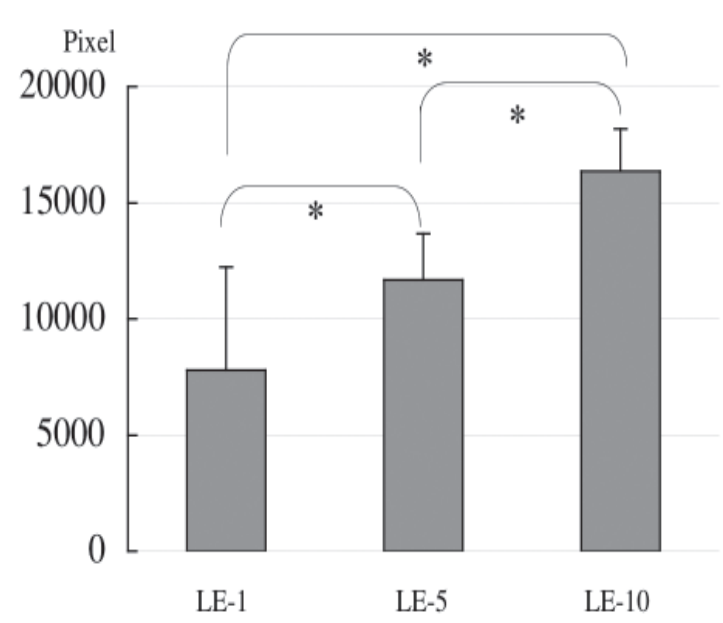

Graph 1.Infiltration area in LE groups. LE-1: 1 min after injection; LE-5: 5 min after injection; LE10: 10 min after injection. Mean $\pm \mathrm{SD}, * \mathrm{p}<0.05$ between 2 groups.

independently acquired with BAS imaging system 2000 (Fuji Film, Japan). The contact time of 90 minutes was determined by a pilot study. Thereafter, specimens were scanned and anatomical imaging data were obtained. Finally, two imaging data were superimposed and the position of the image showing accumulation was determined (Fig. 2).

\section{Measurements}

To measure the infiltration area, regions of accumulation of ${ }^{14} \mathrm{C}$ in images were selected and the area (amount of pixels) was calculated with image analysis software (Image J 1.38v, National Institutes of Health, USA). On Image J, sampling from image obtained with BAS imaging system was made. The pixel size was $100 \mathrm{~nm} \times 100 \mathrm{~nm}$, with a maximum pixel value of 256 and minimum of 0 . The infiltration area was defined as the number of consecutive pixel showing from 40 to 50 in pixel value.

To determine the proportion of distribution, four sites were selected. The selected sites included A: submucosal tissue of the injection site; B: tissue next to periosteal membrane surrounding alveolar bone (approximately $1 / 2$ of tooth length); C: tissue next to periosteal membrane at the level equivalent to the root apex and D: alveolar bone marrow at the level equivalent to the root apex (Fig. 2). Accumulation of ${ }^{14} \mathrm{C}$ in a circle (13 pixels in diameter) of these sites was measured and the ratio of accumulation in the circles of sites B, C and D was compared to that of site A.

\section{Statistical analysis}

All results are shown as the mean \pm standard deviation. Statistical analysis was performed using non-repeated measurements of ANOVA. Multiple comparisons were performed by Student-Newman-Keuls test. A p-value less than 0.05 were considered significant.

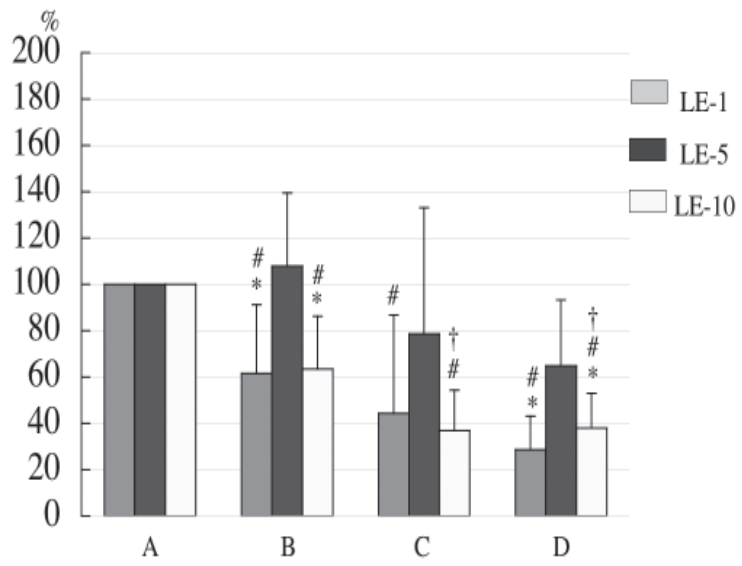

Graph 2. Proportion of lidocaine distribution in LE groups. LE1: 1 min after injection; LE-5: 5 min after injection; LE10: 10 min after injection. A: submucosal tissue of the injection site; B: tissue next to periosteal membrane surrounding alveolar bone (approximately $1 / 2$ of tooth length); C: tissue next to periosteal membrane at a level equivalent to the root apex; D: alveolar bone marrow at a level equivalent to the root apex. Mean $\pm \mathrm{SD}, \# \mathrm{p}<0.05$ vs $\mathrm{A}, * \mathrm{P}<0.05$ vs LE- $5, \uparrow \mathrm{P}<0.05$ vs B.

\section{Results}

\section{Infiltration area (Fig. 3)}

Infiltration areas were $7785.6 \pm 4442.4$ pixels in LE-1 group, $11686.8 \pm 1982.2$ pixels in LE-5 group, and $16363.3 \pm 1821.9$ pixels in LE-10 group (Graph 1). Infiltration area increased over time. In contrast, in the L groups, it was difficult to determine the accumulation area from the surrounding background. The accumulation area could not be identified in some specimens. Infiltration areas were 26444. $5 \pm 110.5$ pixels in L-1 group, observed in 2 specimens and 10150 pixels in L-5 group observed in only 1 specimen. No accumulation was observed in both specimens in L-10 group.

\section{Proportion of distribution}

In LE-1 group, accumulations at sites B, C and D were smaller than that at site A. However, there was no difference among the accumulations at sites $\mathrm{B}, \mathrm{C}$ and $\mathrm{D}$ when compared to each other. In LE-5 group, there was no difference in the accumulations at sites $\mathrm{B}, \mathrm{C}$ and $\mathrm{D}$ from that at site A. In LE-10 group, accumulations at sites $\mathrm{B}, \mathrm{C}$ and $\mathrm{D}$ were smaller than that at site $\mathrm{A}$. In addition, accumulations at sites $\mathrm{C}$ and $\mathrm{D}$ were smaller than that at site $\mathrm{B}$. When each site was compared, accumulations at sites B and D in LE-5 group were greater than those in LE-1 and LE-10 groups, while there was no difference was obtained between those of the LE-1 and LE-10 groups. There was no difference among three groups at site $\mathrm{C}$ (Graph 2). As for the mean value of each site in L-1 group, accumulation at site $B$ tended to increase, while those at sites $\mathrm{C}$ and $\mathrm{D}$ tended to decrease compared with that at site $\mathrm{A}$. In L-5 group, accumulations at site B, C and D tended to decrease compared with that at site A. 


\section{Discussion}

Tissue distribution of local anesthetics has been inferred from anesthetized area after local infiltration. Studies examining anesthetized area used Semmes-Weinstein monofilaments test (unpublished data) or electric tooth pulp stimulation ${ }^{1,2,8,12)}$. However, anesthetized area may not directly reflect the tissue distribution of local anesthetics. We therefore used macroARG to examine the tissue distribution of lidocaine in rabbits. The macroARG method has been used to determine the tissue distribution of several drugs ${ }^{22-24)}$. This method is superior to the conventional method in determining the distribution of drugs and its metabolic pathway including disappearance from tissue in living body because RI can directly label the molecular structure of administered drugs ${ }^{19-21)}$.

The results in the LE groups demonstrated that the infiltration area of lidocaine increased over time after administration. In contrast, in the L groups, accumulation images could not be observed 10 minutes after lidocaine administration. Early recovery from anesthesia was observed after administration of lidocaine without epinephrine ${ }^{1,2)}$. Blood lidocaine concentration reached maximum within 30 - 60 minutes when administered with 1:80,000 epinephrine and within 10 - 20 minutes when administered without epinephrine ${ }^{25)}$. In connection with previous reports, our results suggest that lidocaine may rapidly be absorbed into the capillaries around the site of administration in L group. The difference in accumulation between LE and L groups may reflect the variation in tissue blood flow, which is strongly affected by epinephrine ${ }^{26,27)}$.

In this study, accumulations at each site were measured and the ratio was compared. This was based on the fact that the absolute value of radioactivity has great variations among specimens. Structural differences in individual tissues, differences in the condition of specimens attached to the imaging plate at the time of imaging, and effects of environmental radiation ${ }^{19-21)}$ may explain these discrepancies.

Accumulations at sites B, C and D were smaller than that at site A in LE-1 group. This result suggests that administered lidocaine was mostly retained at the site of injection and did not infiltrate in other areas. In contrast, in LE-5 group, since there was no difference among the sites, it was demonstrated that lidocaine infiltrated widely into other tissues as well as at the injection site. Thereafter, accumulations at sites $\mathrm{B}, \mathrm{C}$ and $\mathrm{D}$ became smaller than that at site $A$ in LE-10 group. In addition, accumulations at sites $\mathrm{C}$ and $\mathrm{D}$ were smaller than that at site $\mathrm{B}$. These results suggested that administered lidocaine might be absorbed into the capillaries in the alveolar bone marrow 10 minutes after injection. As described above, though quantitative comparison could not be performed, it is demonstrated that administered lidocaine infiltrated the surrounding tissues and then gradually into capillaries over time.

Five to ten minutes were required for any type of local anesthetics to develop sufficient anesthetic effects, by comparing the ED50 and ED95 of articaine, propitocaine and lidocaine with different concentrations of epinephrine using the jaw-opening reflex in rabbits ${ }^{6,7)}$. It was also reported that when $2 \%$ lidocaine with 1:100,000 epinephrine was administered to the human mucosa around the upper right canine, the onset time was approximately 3 minutes and the duration of anesthesia was 46.5 minutes ${ }^{10)}$. In the present study, the proportion of distribution of lidocaine at site $\mathrm{D}$ reached the maximum 5 minutes after injection. Therefore, it is suggested that an increase in proportion of lidocaine distribution in the alveolar bone marrow at the level equivalent to the root apex should be important for the onset of anesthetic action.

In this study, the administered dose of lidocaine was determined by weight ratio assuming $1.5 \mathrm{ml}$ of $2 \%$ lidocaine $(30 \mathrm{mg}$ of lidocaine) administered to a $50 \mathrm{~kg}$ patient. This dosage was smaller than those from previous studies ${ }^{10,25)}$. Furthermore, alveolar bone marrow has high-density vessel networks ${ }^{28}$, and it is not clear whether the tissue blood flow in oral mucosa and bone marrow in humans is comparable to those in rabbits. These factors may induce rapid decrease of accumulation in site $\mathrm{D}$, possibly producing shorter duration of anesthesia than in previous studies ${ }^{6,7,10)}$.

There was no difference in the proportion of lidocaine distribution in site $\mathrm{C}$ throughout the experiment. This result might be attributed to individual differences in thickness and density of specimens. Since we did not observe three-dimensional distribution condition, observation of three-dimensional distribution using horizontal and serial sections must be considered in future studies.

In conclusion, infiltration area increased over time in LE group. The proportion of lidocaine distribution in alveolar bone marrow increased up to 5 minutes after administration and then decreased 10 minutes after administration to a level comparable to that at 1 minute.

\section{Acknowledgment}

This work was partly supported by Grant-in-aid for Sientific Research from The Japan Society for promotion Science (18592204). I thank Dr. Kimihide Nakamura (Tokyo Nuclear Services Co., Ltd) and Dr. Kazunori Anzai (National Institute of Radiological Sciences) for valuable technical suggestions.

\section{References}

1. Björn H. The determination of the efficiency of dental local anesthtics. Svensk Tandläkare-Tidskrift 40:771-796, 1947

2. Björn $\mathrm{H}$ and Huldt $\mathrm{S}$. The efficiency of xylocaine as a dental terminal anesthetic compared to that of procaine. Svensk Tandläkare-Tidskrift 40:831-852, 1947

3. Bradley DJ and Martin ND. Clinical evaluation mepivacaine and lidocaine. Aust Dent J 14:377-381, 1969

4. Covino BG. Comparative clinical pharmacology of local 
Takaki Yamazaki et al.: Lidocaine Distribution in Alveolar Tissue in the Rabbit

anesthtic agents. Anesthesiology 35:158-167, 1971

5. Knoll-Köhler E and Förtsch G. Pulpal anesthesia dependent on epinephrine dose in 2\% lidocaine. Oral Surg Oral Med Oral Pathol 73:537-540, 1992

6. Miyoshi T, Aida H and Kaneko Y. Comparative study on anesthetic potency of dental local anesthetics assessed by the jaw-opening reflex in rabbits. Anesth Prog 47:35-41, 2000

7. Ohkado S, Ichinohe T and Kaneko Y. Comparative study on anesthetic potency depending on concentrations of lidocaine and epinephrine: assessment of dental local anesthetics using the jaw-opening reflex. Anesth Prog 48:16-20, 2001

8. Yonchak T, Reader A, Beck M, Clark K and Meyers WJ. Anesthetic efficacy of infiltrations in mandibular anterior teeth. Anesth Prog 48: 55-60, 2001

9. Ernberg M and Kopp S. Ropivacaine for dental anesthesia: A dose-finding study. J Oral Maxillofac Surg 60:1004-1010, 2002

10. Oliveira PC, Volpato MC, Ramacciato JC and Ranali J. Articaine and lignocaine efficiency in infiltration anaesthesia: a pilot study. Br Dent J 197:45-46, 2004

11. Costa CG, Tortamano IP, Rocha RG, Francischone CE and Tortamano N. Onset and duration periods of articaine and lidocaine on maxillary infiltration. Quintessence Int 36:197201, 2005

12. Kanaa MD, Whitworth JM, Corbett IP and Meechan JG. Articaine and lidocaine mandibular buccal infiltration anesthesia: a prospective randomized double-blind cross-over study. J Endod 32:296-298, 2006

13. Ito E, Ichinohe T, Shibukawa Y, Aida H and Kaneko Y. Anesthetic duration of lidocaine with $10 \%$ dextran is comparable to lidocaine with 1:160 000 epinephrine after intraosseous injection in the rabbit. Oral Surg Oral Med Oral Pathol Oral Radiol Endod 104:26-31, 2007

14. Tagger E, Tagger $M$ and Sarnat H. Periodontal ligament injection: spread of the solution in the dog. J Endod 20:2837, 1994

15. Tagger E, Tagger M, Sarnat H and Mass E. Periodontal ligament injection in the dog primary dentition : spread of local anaesthetic solution. Int J Paediatr Dent 4:159-166, 1994

16. Pettersson LO and Akerman B. Influence of hyaluronidase upon local infiltration anaesthesia by lidocaine. Scand J Plast Reconstr Surg 18:297-301, 1984

17. Lewis-Smith PA. Adjunctive use of hyaluronidase in local anaesthesia. Br J Plast Surg 39:554-558, 1986

18. Moorthy SS, Dierdorf SF and Yaw PB. Influence of volume on the spread of local anesthetic-methylene blue solution after injection for intercostal block. Anesth Analg 175:38991, 1992

19. Motoji N., Hayama E. and Shigematsu A. Studies on the quantitative autoradiography. I. Radioluminography for quantitative autoradiography of 14C. Biol Pharm Bull 18(1): 89-93, 1995

20. Yamane Y., Ishide N., Kagaya Y., Takeyama D., Shiba N., Chida M., Sekiguchi Y., Nozaki T., Ido T. and Shirato K. Quantitative double-tracer autoradiography with tritium and carbon-14 using imaging plates: application to myocardial metabolic studies in rats. J Nucl Med 36(3): 518-24, 1995

21. Motoji N., Hayama E. and Shigematsu A. Radioluminography for quantitative autoradiography of 14C. Eur J Drug Metab Pharmacokinet 20(2): 89-105. 1995

22. Martin J.H. Autoradiographic estimation of the extent of reversible inactivation produced by microinjection of lidocaine and muscimol in the rat. Neurosci Lett 127: 160164, 1991

23. Distribution of radioactivity in bone and related structures following administration of [14C]dalbavancin to New Zealand White rabbits. Antimicrob Agents Chemother 51: 3008-3010, 2007

24. Roehm P., Hoffer M. and Balaban C.D. Gentamicin uptake in the chinchilla inner ear. Hear Res 230: 43-52, 2007

25. Cannell H., Walters H., Beckett A.H. and Saunders A. Circulating levels of lignocaine after peri-oral injections. $\mathrm{Br}$ Dent J 138: 87-93, 1975

26. Suzuki T., Sano K. and Kanri T. Influence of various local anesthetics on peripheral blood flow in human gingiva. Anesth Prog 36: 178-191, 1989

27. Homma Y., Ichinohe T. and Kaneko Y. Oral mucosal blood flow, plasma epinephrine and haemodynamic responses after injection of lidocaine with epinephrine during midazolam sedation and isoflurane anaesthesia. Br J Anaesth 82: 570574, 1999

28. Kaneko Y. Experimental studies on vascualr changes in fractures and osteomyelitis. 1. Vascular changes in mandibular fracture and healing. Bull.Tokyo dent. 9: 123146, 1968 
J.Hard Tissue Biology Vol. 18(2):95-100, 2009 